\title{
Registro de Nystalea nyseus (CRAMER, 1775) em Eucalyptus saligna Smith no Estado do Rio Grande do Sul
}

\author{
Record of Nystalea nyseus (CRAMER, 1775) in Eucalyptus saligna Smith in Rio Grande do Sul \\ State, Brazil
}

\begin{abstract}
Iris Cristiane Magistrali ${ }^{*}$ Ervandil Corrêa Costa ${ }^{\mathrm{I}}$ Juliana Garlet ${ }^{\mathrm{I}}$ Jardel Boscardin $^{\mathrm{I}}$ Leonardo Mortari Machado ${ }^{\mathrm{I}}$ Norton Borges Júnior ${ }^{\mathrm{II}}$
\end{abstract}

\section{- NOTA -}

\section{RESUMO}

Este trabalho objetivou relatar o ataque de lagartas desfolhadoras de eucalipto no Estado do Rio Grande do Sul. A espécie foi determinada como sendo Nystalea nyseus (CRAMER, 1775) (Lepidoptera: Notodontidae). As lagartas dessa espécie causam desfolhamento em árvores de eucalipto. Este é o primeiro registro de Nystalea nyseus em árvores de eucalipto no Estado.

Palavras-chave: desfolhador de eucalipto, entomologia florestal, Notodontidae.

\section{ABSTRACT}

This research aimed to record the damage caused by encalyptus-defoliating caterpillars located in Rio Grande do Sul States, Brazil. The specie was determined as Nystalea nyseus (CRAMER, 1775) (Lepidoptera: Notodontidae). The caterpillars of this species cause defoliation in eucalyptus trees. This is the first record of Nystalea nyseus from eucalyptus plantation in the Rio Grande do Sul State, Brazil.

Key words: Eucaliptus defoliator, forest entomology, Notodontidae.

No Brasil, espécies do gênero Eucalyptus são amplamente cultivadas em plantios homogêneos e ocupam atualmente uma área de 4.754 .334 milhões de hectares (ABRAF, 2011). O aumento da área plantada com espécies pertencentes a este gênero propicia o ataque de um número significativo de insetos-praga. Dentre aquelas que atacam o eucalipto, encontram-se os lepidópteros desfolhadores. Esse grupo tem, como hospedeiros de origem, mirtáceas nativas, nas quais não se tem observado surtos populacionais (ANJOS et al., 1987).

No Brasil, surtos de lagartas desfolhadoras em eucalipto já foram relatados por ZANUNCIO \& LIMA (1975), ANJOS et al. (1981), SANTOS et al. (1986), SANTOS et al. (1993). Entre as principais espécies de lepidópteros nativos registradas atacando o eucalipto, destacam-se: Eupseudosoma aberrans Schaus e Eupseudosoma involuta Sepp (Arctiidae), Sabulodes caberata Guenée, Thyrinteina arnobia (Stoll) e Oxydia vesulia Cramer (Geometridae), Automeris sp. Walker e Eacles imperiales Walker (Saturniidae) (ZANUNCIO et al., 1990).

A espécie Nystalea nyseus (CRAMER, 1775) tem sido capturada frequentemente com armadilhas luminosas em diferentes regiões do Brasil (ZANUNCIO et al., 1994). No Estado do Rio Grande do Sul, lagartas dessa espécie já foram registradas associadas a plantas de goiaba (Psidium guajava), araçazeiro (Psidium catteleianum), camboatá (Blighia vernalis) e eucaliptos (BIEZANKO, 1962). Surtos de lepidópteros desfolhadores já foram registrados no Estado do Rio Grande do Sul, como o de Euselasia euploea eucerus (Hewitson, 1872) (Riodinidae) que causou danos significativos em Eucalyptus alba (FAGUNDES et al., 1983). Em povoamentos de Acacia mearnsii De Wild, foram registradas as espécies Adeloneivaia

IDepartamento de Defesa Fitossanitária, Universidade Federal de Santa Maria (UFSM), Campus Universitário, Av. Roraima, 1000, prédio 42, Bairro Camobi, 97105-900, Santa Maria, RS, Brasil. E-mail: irismagistrali@gmail.com. *Autor para correspondência.

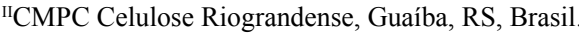


subangulata (Herrich-Schaeffer, 1855) Attacidae e Thyrinteina arnobia (Stoll, 1782) (Geometridae), respectivamente, por BRESSAN \& SANTOS (1985) e TARRAGÓ \& COSTA (1990).

Para o Estado do Rio Grande do Sul, não havia registro de Nystalea nyseus em forma de surto. Portanto, o objetivo deste trabalho é relatar a ocorrência de um surto deste inseto, bem como descrever seus danos.

No mês de abril de 2011, foi observado um surto de lagartas desfolhadoras em árvores de Eucalyptus saligna Smith de 2 anos e oito meses em 77 hectares, plantadas em espaçamento $3,5 \mathrm{~m} \times 2,14 \mathrm{~m}$, localizadas no Horto Florestal Boa Aguada, $\left(30^{\circ} 12^{\prime} 97^{\prime \prime} \mathrm{S}\right.$ e $\left.53^{\circ} 35^{\prime} 63^{\prime} \mathrm{W}\right)$, município de São Sepé, Rio Grande do Sul. Os adultos foram identificados como Nystalea nyseus (CRAMER, 1775) (Lepidoptera: Notodontidae) pelo prof. Dr. Sinval Silveira Neto do Museu de Entomologia da Universidade de São Paulo, USP.

Foram realizadas amostragens em cinco talhões $(01,02,03,04,05)$ do Horto Florestal atacados por $N$. nyseus. Para a amostragem, utilizouse o método de transecto, partindo-se da borda em direção ao centro do talhão, avaliando uma linha de plantio a cada 25 linhas. Para a classificação da infestação, foram atribuídos valores de presença (1) e ausência (0) de ataque.

Também foi avaliada a porcentagem de ataque nos terços superior, médio e inferior das copas. $\mathrm{O}$ terço inferior é definido como a parte que compreende até dois metros no sentido base ápice da árvore, terço médio, de dois a quatro metros, e terço superior, aquele que compreende a última porção da árvore.

A partir dos dados observados, constatouse a presença de ataque em todos os talhões avaliados. Os talhões 01,02 e 03 apresentaram maior porcentagem de ataque com $79 \%, 67 \%$ e $62 \%$, respectivamente, seguidos dos talhões 04 e 05 com $42 \%$ e $25 \%$ de ataque. A intensidade de ataque, entretanto, foi maior nas bordaduras dos talhões em relação às áreas internas.

Nos talhões 01 e 02 , onde $o$ ataque foi mais severo, verificou-se que o desfolhamento ocorreu predominantemente no terço inferior e médio da copa com $73,4 \%$ e $67 \%$, respectivamente. Nos demais talhões, os danos estavam presentes apenas na parte inferior da copa. ODA \& BERTI FILHO (1978) verificaram que a perda de volume no incremento médio anual de árvores de Eucalyptus saligna pode chegar a $40 \%$ em árvores que tiveram a parte vegetativa totalmente destruída em função do ataque da espécie Thyrinteina arnobia. Apesar da espécie
Nystalea nyseus ter sido registrada em outras regiões do Brasil, não existem trabalhos que relatem a perda em volume em plantios de eucaliptos atacados por essa espécie.

Visualizou-se a campo árvores totalmente infestadas, apresentando grande quantidade de lagartas subindo pelo tronco no sentido da base para o ápice. O dano de lagartas de $\boldsymbol{N}$. nyseus caracterizase pelo consumo de folhas de eucalipto, no sentido do pecíolo para a margem, e, em caso severo, pode restar apenas a nervura central. Além disso, o ataque ocasiona queda prematura de folhas o que pode comprometer o volume de madeira.

As fêmeas de $N$. nyseus colocam ovos de coloração verde-escura, que posteriormente tornam-se manchados de vermelho e após 48 horas apresentam coloração vermelho-escura. As lagartas são conhecidas popularmente como "lagarta-dragão" em função das protuberâncias dorsais, principalmente nos últimos segmentos abdominais, as quais adquirem a forma de uma cabeça, lembrando um "dragão" (ZANUNCIO et al., 1994). A ocorrência de um surto de $N$. nyseus em Eucalyptus saligna é um fato novo e relevante para a eucaliptocultura no Rio Grande do Sul, tendo em vista a densidade populacional e a voracidade que as lagartas de $\boldsymbol{N}$. nyseus apresentam. Alerta-se para possíveis surtos desse inseto-praga em plantios de eucalipto no Estado.

\section{AGRADECIMENTOS}

Ao prof. Dr. Sinval Silveira Neto do Museu de Entomologia da Universidade de São Paulo USP, pela identificação da espécie. À Coordenação de Aperfeiçoamento de Pessoal de Nível Superior (CAPES) e ao Conselho Nacional de Desenvolvimento Científico e Tecnológico (CNPQ), pelo apoio financeiro.

\section{REFERÊNCIAS}

ABRAF (ASSOCIAÇÃO BRASILEIRA DE FLORESTAS PLANTADAS). 2011. Estatísticas. Disponível em: <http:// www.abraflor.org.br/estatisticas/ABRAF11/ABRAF11-BR.pdf> . Acesso em: 14 mar. 2011.

ANJOS, N.S. et al. Ocorrência de Thyrinteina arnobia (Stoll, 1792) (Lepidoptera: Geometridae) em eucaliptais de Minas Gerais. In: CONGRESSO BRASILEIRO DE ENTOMOLOGIA, 6., 1981, Fortaleza, CE. Resumos... Fortaleza: Sociedade Brasileira de Entomologia, 1981. V.1, p.94.

ANJOS, N. et al. A lagarta-parda, Thyrinteina arnobia (Stoll, 1782) (Lepidoptera, Geometridae) desfolhadora de eucaliptos. Boletim Téenico. Empresa de Pesquisa Agropecuária de Minas Gerais, Belo Horizonte, v.25, p.1-56, 1987.

BIEZANKO, C.M. Notodontidae et Dioptidae da Zona Sueste do Rio Grande do Sul. Arquivos de Entomologia. Série A, n.8, p.114, 1962. 
BRESSAN, D.A.; SANTOS, H.R. dos. Avaliação da densidade, viabilidade e do parasitismo em pupas de Adeloneivaia subangulata (Herrich-Schäffer, 1855) Travassos, 1940 (Lep., Attacidade) em povoamentos de Acacia mearnsii (de Wild.). Revista Floresta, v.15, n.1 e 2, p.38-42, 1985. Disponível em: <http://ojs.c3sl.ufpr. br/ojs2/index.php/floresta/article/viewArticle/6360>. Acesso em: 18 ago. 2011.

FAGUNDES, A. C. et al. Ocorrência e controle natural da lagarta do Eucalipto Euselasia euploea eucerus no Rio Grande do Sul. Revista Trigo e Soja, v.68, p.27-30, 1983.

ODA, S.; BERTI FILHO, E. Incremento anual volumétrico de Eucalyptus saligna $\mathrm{Sm}$. em áreas com diferentes níveis de infestação de lagartas de Thyrinteina arnobia (Stoll, 1782) (Lepidoptera, Geometridae). Instituto de Pesquisa e Estudos Florestais - IPEF, v.17, p.27-31, 1978. Disponível em: <www.ipef.br/publicacoes/ scientia/nr17/cap03.pdf>. Acesso em: 17 ago. 2011.

SANTOS, G.P. et al. Bionomia de Oxydia vesulia (Cramer, 1779) (Lepidoptera: Geometridae), desfolhador de eucalipto. Revista Árvore, v.10, n.2, p.161-167, 1986.

SANTOS, G. P. et al. Descrição das lagartas desfolhadoras. In: ZANUNCIO, J.C. (Coord.). Manual de pragas em florestas.
Lepidoptera desfolhadores de eucalipto: biologia, ecologia e controle. Viçosa: Folha de Viçosa 1993. 140p.

TARRAGÓ, M.F.S.; COSTA, E.C. Ocorrência de Thyrinteina arnobia (Stoll, 1782) (Lepidoptera, Geometridae), em Acácia negra no Rio Grande do Sul. Revista Centro de Ciências Rurais, v.20, n.3-4, p.219-221, 1990. Disponível em: <http:// cascavel.ufsm.br/revista_new/ojs/index.php/RCCCR/article/ view/737/734>. Acesso em: 14 ago. 2011.

ZANUNCIO, J.C.; LIMA, J.O.G. Ocorrência de Sarsina violascens (Herrich - Schaeffer, 1856) (Lepidoptera: Lymantriidae) em eucaliptos de Minas Gerais. Brasil Florestal, v.6, n.23, p.4850,1975 .

ZANUNCIO, J.C. et al. Levantamento e flutuação populacional de lepidópteros associados a eucaliptocultura: V- Região de Belo Oriente, MG., Junho de 1986 A Maio de 1987. Revista Árvore, v.14, n.1, p.35-44, 1990.

ZANUNCIO, T.V. et al. Biologia de Nystalea nyseus (Cramer, 1775) (Lepidoptera: Notodontidae) em folhas de Eucalyptus urophylla. Acta Amazonica, v.24, n.212, p.153-160, 1994. Disponível em: <acta.inpa.gov.br/fasciculos/24-2/PDF/v24n2a15. pdf $>$. Acesso em: 12 ago. 2011.

Ciência Rural, v.43, n.5, mai, 2013. 